\title{
Haemodynamic effects of hydralazine at rest and during exercise in patients with chronic heart failure
}

\author{
WILLIAM R GINKS, DAVID R REDWOOD \\ From the Cardiac Department, St. George's Hospital, London
}

SUMMARY The administration of vasodilator drugs has been shown to have beneficial effects at rest in patients with acute or chronic heart failure. To determine the efficacy of hydralazine during exercise, 10 severely symptomatic patients with chronic left ventricular failure from diffuse coronary disease or cardiomyopathy were studied at rest and during upright exercise on a bicycle ergometer. All patients were already receiving optimal treatment with digitalis and diuretics.

At rest treatment with hydralazine resulted in a fall in both mean arterial and pulmonary wedge pressure. There was a 50 per cent reduction in systemic vascular resistance compared with pretreatment measurements and there was an equally impressive increase in stroke volume index. During exertion the changes noted at rest were sustained though occurred to a lesser degree; thus there was a 20 per cent fall in arterial resistance and a 20 per cent rise in stroke volume index compared with control.

These findings show that hydralazine administration not only results in a beneficial effect on cardiac function at rest but that this effect is maintained during upright exercise in patients with impaired left ventricular function, thus providing further support for its use in the long-term management of such patients.

The improvement in survival of patients admitted to coronary care units with acute myocardial infarction and the reduction in post-infarct mortality with the use of antiarrhythmic treatment has resulted in an increasing number of patients who manifest symptoms and signs of poor ventricular function and in whom the use of conventional antifailure treatment with digitalis and diuretics has failed to result in significant improvement. In these patients and in patients with ventricular failure resulting from other forms of cardiomyopathy, the administration of vasodilator drugs has been shown to result in beneficial haemodynamic changes. ${ }^{1-6}$

Thus sodium nitroprusside given intravenously lowers systemic vascular resistance and reduces impedance to ventricular ejection. Consequently cardiac output increases with only small changes in the arterial pressure. At the same time, because of more effective ventricular emptying and because of an increase in venous capacitance consequent upon the venodilatory effects of nitroprusside, ventricular filling pressures are reduced. Thus the two major effects of chronic pump failure are alleviatedReceived for publication 15 October 1979 namely impaired organ perfusion and raised pulmonary venous pressure. While these beneficial effects follow the acute administration of intravenous sodium nitroprusside, its use in the longterm management of heart failure is clearly not feasible. Further studies have therefore examined the effects of other vasodilator drugs which can be administered orally. Nitrates qualitatively mimic the effects of treatment with nitroprusside by causing a significant reduction in left ventricular filling pressure ${ }^{7} 8$ but a less impressive change in cardiac output. ${ }^{9} 10$

Treatment with hydralazine, an arterial dilator, increases the cardiac output as much as nitroprusside but seems to be less effective in reducing left ventricular filling pressure. ${ }^{11-16}$

These studies have analysed the acute effects of drugs used at rest and little attention has been paid to their effects during upright exercise where the major benefit of such treatment would be sought. The present study has therefore been undertaken to assess the haemodynamic effects of orally admininistered hydralazine, at rest and during upright bicycle exercise, in patients with chronic left ventricular failure from myocardial disease. 
Table 1 Haemodynamic effects of hydralazine at rest

\begin{tabular}{|c|c|c|c|c|c|c|c|c|c|c|c|}
\hline \multirow[b]{2}{*}{$\begin{array}{l}\text { Case } \\
\text { no. }\end{array}$} & \multirow[b]{2}{*}{ Aet } & \multicolumn{7}{|c|}{ Before drug } & \multicolumn{2}{|c|}{ After drug } & 믐 \\
\hline & & $\begin{array}{l}H R \\
(b / \min )\end{array}$ & $\begin{array}{l}M P A P \\
(m \boldsymbol{m} H \boldsymbol{g})\end{array}$ & $\begin{array}{l}P C W P \\
(\mathbf{m m H g})\end{array}$ & $\begin{array}{l}M A P \\
(\boldsymbol{m} \boldsymbol{m} H \boldsymbol{g})\end{array}$ & $\begin{array}{l}C I \\
\left(l / \min \text { per } m^{2}\right)\end{array}$ & $\begin{array}{l}S V R \\
\text { units }\end{array}$ & $\begin{array}{l}S V I \\
\left(\mathrm{ml} / \mathrm{m}^{2}\right)\end{array}$ & $\begin{array}{l}H R \\
(b / \min )\end{array}$ & $\begin{array}{l}M P \\
(\boldsymbol{m} \boldsymbol{n}\end{array}$ & Aक \\
\hline 1 & CD & 100 & 47 & 28 & 100 & 1.50 & 40 & 15 & 98 & 55 & \\
\hline 2 & CD & 89 & 35 & 27 & 80 & 1.252 & 29 & 17 & 85 & 35 & ڤ్ \\
\hline 3 & CD & 105 & 16 & 5 & 84 & 1.49 & 31 & 14 & 107 & 12 & \\
\hline 4 & $\mathrm{CD}$ & 100 & 25 & 16 & 80 & 2.053 & 24 & 20 & 100 & 25 & 0 \\
\hline 3 & CD & 90 & 29 & 22 & 80 & 2.053 & 24 & 23 & 100 & 32 & \\
\hline 6 & CD & 90 & 13 & 8 & 92 & $2 \cdot 455$ & 24 & 27 & 85 & 13 & \\
\hline 7 & $\mathrm{CM}$ & 70 & 26 & 18 & 90 & 1.60 & 27 & 23 & 70 & 20 & 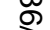 \\
\hline 8 & $\mathrm{CM}$ & 135 & 18 & 5 & 88 & 1.98 & 26 & 15 & 162 & 17 & \\
\hline 9 & AVR & 63 & 57 & 32 & 92 & 1.672 & 31 & 27 & 68 & 54 & \\
\hline 10 & $\mathrm{CM}$ & 90 & 25 & 17 & 84 & 2.535 & 18 & 28 & 90 & 22 & + \\
\hline \multicolumn{2}{|c|}{$\begin{array}{r}\text { Group data } \\
(\mathrm{SEM} \pm)\end{array}$} & $93 \pm 6$ & $29 \pm 4$ & $18 \pm 3$ & $87 \pm 2$ & $1.886 \pm 0.12$ & $27 \pm 2$ & $21 \pm 2$ & $97 \pm 8$ & & \\
\hline
\end{tabular}

HR, heart rate; MPAP, mean pulmonary artery pressure; PCWP, pulmonary capillary wedge pressure; CI, cardiac index; MAP, mean arterial $O$ pressure; SVR, systemic vascular resistance; SVI, stroke volume index; CD, coronary artery disease; CM, dilated cardiomyopathy; AVR, aortic valve replacement.

\section{Patients and methods}

Ten patients with chronic heart failure were studied. There were seven men and three women, with an age range of 44 to 72 years (mean 61 years). The aetiology of the ventricular failure was secondary to diffuse coronary arterial disease in six patients, caused by cardiomyopathy of unknown cause in three patients, and was related to persistent poor ventricular function despite aortic valve replacement for severe aortic regurgitation in one patient. Clinically, all patients had symptoms and signs of chronic severe biventricular failure and the chest $x$-ray showed typical cardiomegaly and evidence of pulmonary venous hypertension. All patients were being optimally treated with conventional treatment including digoxin and diuretics.

Before the definitive haemodynamic evaluation, each patient participated in at least two exercise practice sessions in order to become familiar with the bicycle ergometer procedure and in order to assess maximum exercise capacity. Exercise was performed at an initial workload of 20 watts and was increased by 20 watts every three minutes. Exercise continued until the patient felt unable to proceed because of severe dyspnoea or fatigue. Exercise tolerance on the ergometer during the preliminary studies was found to be reproducible in all patients.

During the definitive haemodynamic studies, arterial pressure was measured by means of a short Teflon catheter inserted percutaneously into the brachial artery. Pulmonary capillary wedge pressure was obtained by inserting a balloon-tipped triple lumen catheter through a basilic vein. Cardiac output was determined in triplicate using thermodilution techniques. For convenience, pressure measurements were made with zero reference to

Table 2 Haemodynamic effects of hydralazine during exercise

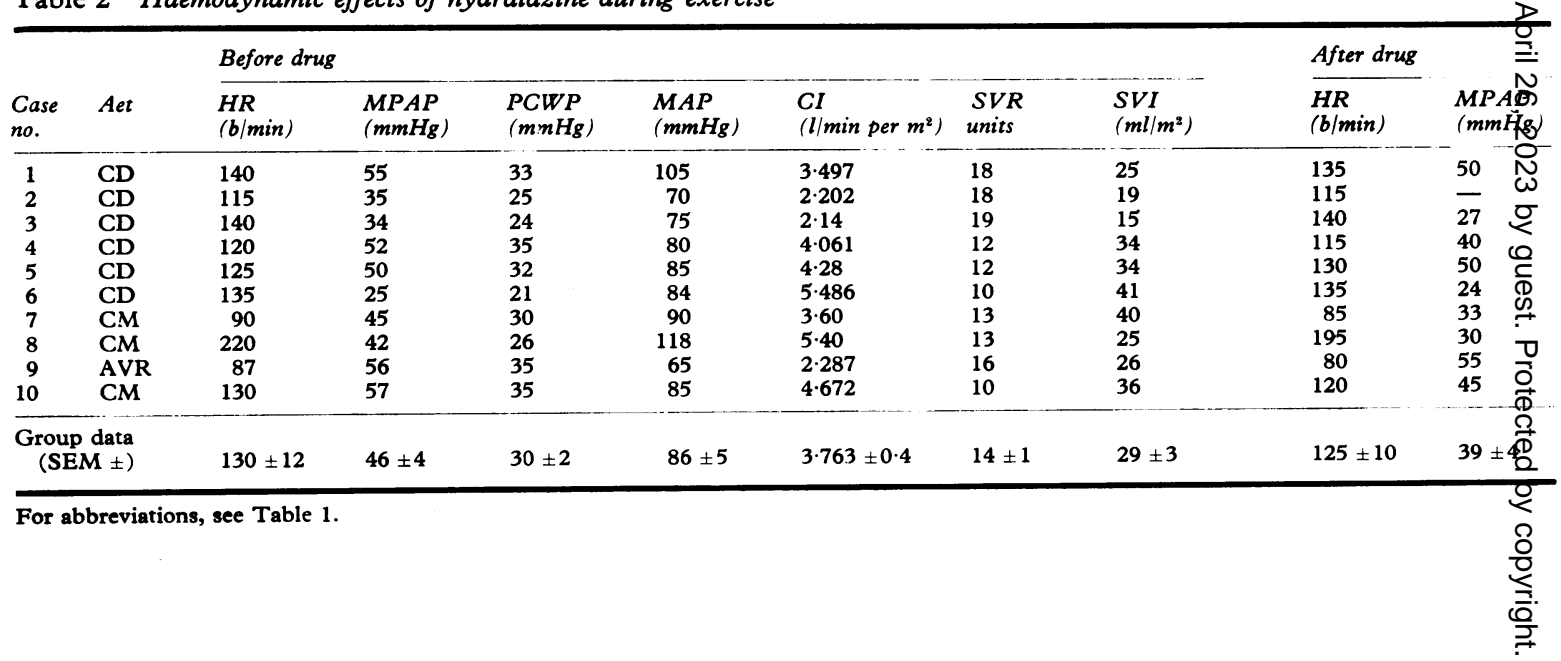




\begin{tabular}{lllll}
\hline $\begin{array}{l}P C W P \\
\left(m m H_{g}\right)\end{array}$ & $\begin{array}{l}M A P \\
\left(m m H_{g}\right)\end{array}$ & $\begin{array}{l}C I \\
\left(l / m i n \text { per } m^{2}\right)\end{array}$ & $\begin{array}{l}S V R \\
\text { units }\end{array}$ & $\begin{array}{l}S V I \\
\left(m^{\prime} / m^{2}\right)\end{array}$ \\
\hline 30 & 94 & $1 \cdot 887$ & 30 & 19 \\
22 & 74 & $2 \cdot 279$ & 18 & 27 \\
2 & 62 & $2 \cdot 314$ & 15 & 22 \\
15 & 70 & $3 \cdot 794$ & 11 & 38 \\
20 & 80 & $3 \cdot 159$ & 16 & 32 \\
3 & 54 & $3 \cdot 454$ & 10 & 41 \\
5 & 65 & $3 \cdot 10$ & 11 & 44 \\
4 & 60 & 3.60 & 10 & 22 \\
30 & 69 & 2.663 & 15 & 39 \\
10 & 78 & 3.937 & 11 & 44 \\
\hline
\end{tabular}

exercise, before and three hours after the oral administration of hydralazine.

Under resting conditions hydralazine produced a significant fall in mean pulmonary venous pressure from an average of $18 \pm 3.0$ to $14 \pm 3.5 \mathrm{mmHg}$ $(p<0.05)$; at peak exercise, a significant reduction in mean wedge pressure also occurred after treatment, from $30 \pm 1.6$ to $23 \pm 1.1 \mathrm{mmHg}(p<0.01)$ (Fig. 1). Similar haemodynamic effects on mean arterial pressure were observed. Thus mean arterial pressure fell from $87 \pm 2 \cdot 1$ to $70 \pm 3.6 \mathrm{mmHg}$ $(\mathrm{p}<0.01)$ after treatment at rest and from $86 \pm 5.0$ to $76 \pm 3.9 \mathrm{mmHg}(\mathrm{p}<0.01)$ during peak exercise (Fig. 2). The fall in arterial pressure was related to a striking reduction in arterial resistance. At rest, arterial resistance fell from an average of $27 \pm 1.9$

the sternal angle. Baseline haemodynamic measurements were obtained with the patient sitting upright at rest on the bicycle ergometer. The patient then performed graded exercise to the point of maximal exercise tolerance when haemodynamic recordings were repeated before the termination of exercise with dyspnoea or fatigue. After this control study the patients rested supine and were given $\mathbf{5 0}$ to $75 \mathrm{mg}$ hydralazine orally (a dose of $1 \mathrm{mg} / \mathrm{kg}$ body weight was given based on earlier haemodynamic observations). Cardiac output determinations and pressure measurements were repeated at rest and during maximum exertion three hours later.

\section{Results}

Tables 1 and 2 show the haemodynamic variables in the 10 patients both at rest and during maximal

\begin{tabular}{lllll}
\hline $\begin{array}{l}P C W P \\
(m m H g)\end{array}$ & $\begin{array}{l}M A P \\
(m m H g)\end{array}$ & $\begin{array}{l}C I \\
\left(l / m i n \text { per } m^{2}\right)\end{array}$ & $\begin{array}{l}S V R \\
\text { units }\end{array}$ & $\begin{array}{l}S V I \\
\left(m l / m^{2}\right)\end{array}$ \\
\hline 30 & 94 & $3 \cdot 845$ & 15 & 29 \\
20 & 60 & $2 \cdot 345$ & 14 & 21 \\
22 & 67 & $2 \cdot 656$ & 14 & 19 \\
25 & 70 & $4 \cdot 897$ & 9 & 43 \\
30 & 86 & $4 \cdot 669$ & 12 & 36 \\
12 & 70 & $5 \cdot 075$ & 9 & 38 \\
15 & 84 & $4 \cdot 40$ & 9 & 53 \\
20 & 88 & $6 \cdot 1$ & 8 & 31 \\
30 & 60 & $3 \cdot 087$ & 11 & 39 \\
30 & 80 & $5 \cdot 768$ & 8 & 48 \\
\hline
\end{tabular}

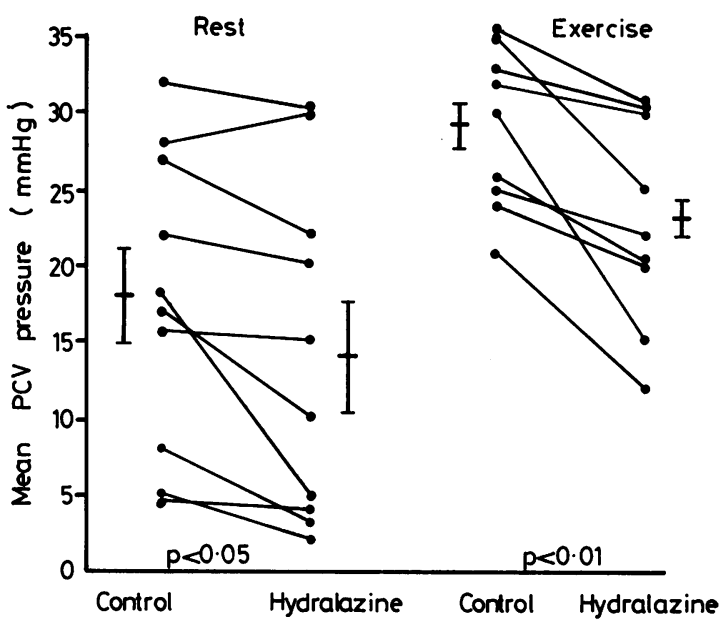

Fig. 1 The haemodynamic effects of hydralazine on mean pulmonary capillary venous pressure (SEM shown) both at rest (left-hand panel) and during upright exercise (right-hand panel).

units, for the group as a whole, to $15 \pm 1.9$ units $(p<0.01)$ after treatment with hydralazine. As can be seen (Fig. 3) this was similar to the average level of resistance measured in the patients during exercise before hydralazine had been given. During exercise three hours after the drug, there was then a further significant reduction in resistance to $11 \pm 0.8$ units $(p<0.01)$. Coincident with the alteration in systemic vascular resistance, there was an impressive increase in stroke volume both at rest and during maximal exertion (Fig. 4). At rest, stroke volume increased significantly from an average of $21 \pm 1.7$ to $33 \pm 3.1 \mathrm{ml} / \mathrm{m}^{2}$ after hydralazine $(p<0.01)$ and indeed returned to the normal range $\left(>35 \mathrm{ml} / \mathrm{m}^{2}\right)$ in several instances. During effort stroke volume increased from a mean of 


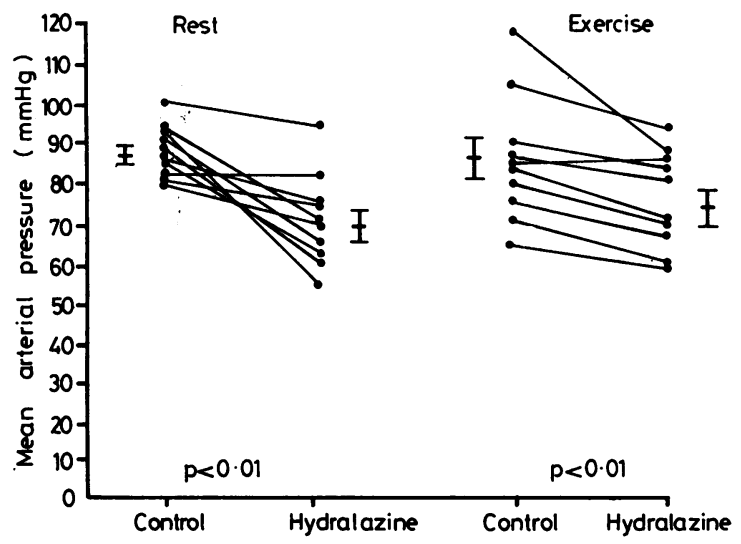

Fig. 2 The haemodynamic effects of hydralazine on mean arterial pressure (SEM shown) both at rest (left-hand panel) and during upright exercise (right-hand panel).

$29 \pm 2 \cdot 8$ to $36 \pm 3.4 \mathrm{ml} / \mathrm{m}^{2}$ after treatment $(\mathrm{p}<0.01)$. In one patient stroke volume actually fell during exertion after hydralazine ( 41 to $38 \mathrm{ml} / \mathrm{m}^{2}$ ) and this was probably related to an excessive reduction in filling pressure induced by the drug in this patient.

The haenodynamic changes occurring after treatment with hydralazine may be expressed as the average percentage change compared with pretreatment measurements. At rest, there was a significant reduction in both arterial and pulmonary

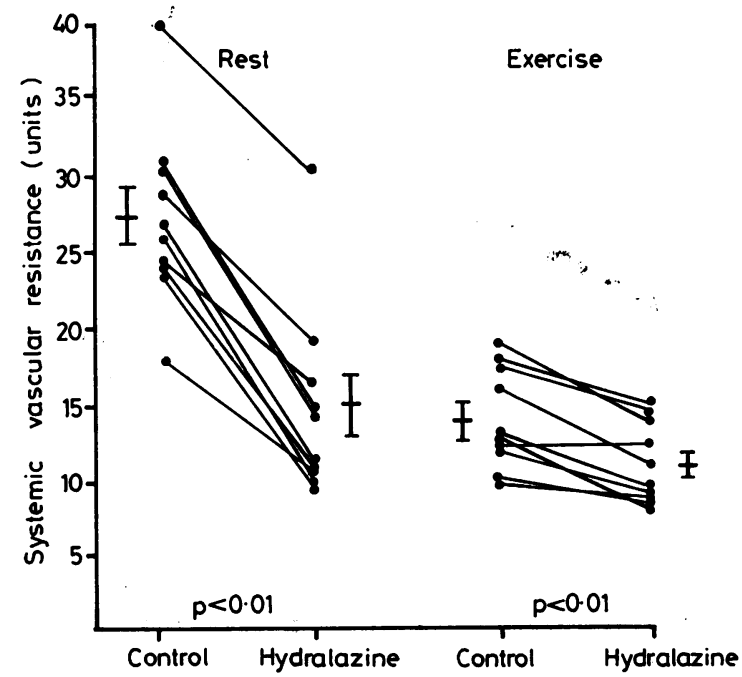

Fig. 3 The haemodynamic effects of hydralazine on systemic vascular resistance (SEM shown) both at rest (left-hand panel) and during upright exercise (right-hand panel).

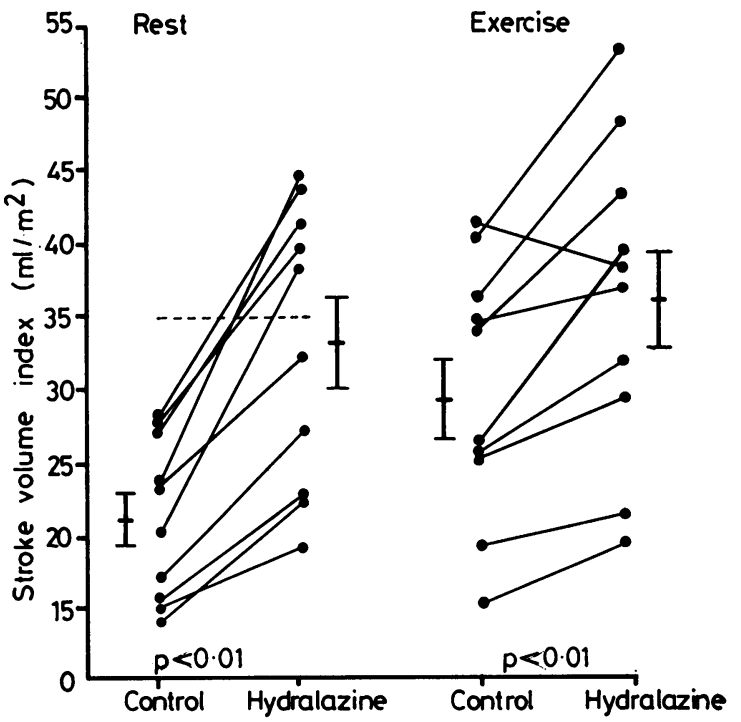

Fig. 4 The haemodynamic effects of hydralazine on stroke volume index (SEM shown) both at rest (left-hand panel) and during upright exercise (right-hand panel).

wedge pressure. There was a 50 per cent reduction in systemic vascular resistance and an equally striking increase in stroke volume index. During exertion the shifts seen in the resting state were maintained but occurred to a considerably lesser degree; thus there was a 20 per cent fall in systemic vascular resistance and a 20 per cent rise in stroke volume index compared with control. In order to analyse the effects of hydralazine on left ventricular performance, points on the function curve were plotted in the conventional manner by comparing the average pulmonary wedge pressure with the average stroke volume index, both at rest and at peak exercise (Fig. 5). At rest, stroke volume index increased from 21 to $33 \mathrm{ml} / \mathrm{m}^{2}$ after hydralazine while there was a coincident slight but significant reduction in filling pressure (from 18 to $14 \mathrm{mmHg}$ ). During exercise treatment with hydralazine resulted in a similar directional change in stroke volume (from 29 to $36 \mathrm{ml} / \mathrm{m}^{2}, \mathrm{p}<0.01$ ). Thus there appeared to be an overall shift of the function curve upwards and to the left suggesting improved left ventricular function.

\section{Discussion}

Systemic vascular resistance is increased in the setting of chronic left ventricular failure since arterial pressure is often normal or sometimes raised in the face of a pronounced reduction in cardiac output. ${ }^{17}$ Multiple factors may be respon- 


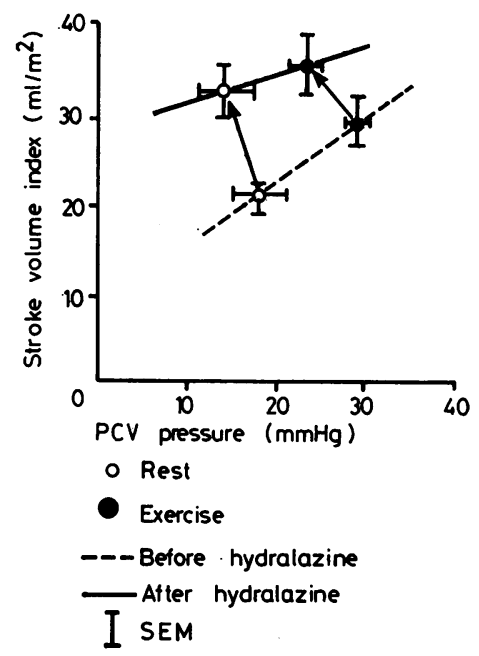

Fig. 5 The effect of hydralazine on left ventricular performance both at rest (left-hand side) and during maximal exertion (right-hand side).

sible for this high vascular resistance. Increased sympathetic outflow, enhanced secretion of renin, and the accumulation of salt and water in the blood vessels may each be determinants in the process. ${ }^{18} 19$

An increase in systemic vascular resistance in response to a decrease in cardiac output is appropriate and beneficial when a fall in cardiac output is not associated with primary pump dysfunction but, in contrast, when left ventricular function is impaired, the increase in impedance further diminishes cardiac output and consequently further compromises the already decreased function. Vasodilator therapy therefore represents a means of interrupting an undesirable positive feedback mechanism that may play an important part in the natural history of heart failure. The overall improvement in cardiac function with hydralazine is most probably the result of a direct dilating effect on resistance vessels previously noted by others. ${ }^{11-14}$ The decrease in impedance to left ventricular ejection shown in this study is therefore presumably responsible for the increase in cardiac output and is similar to the observations, measured under resting conditions, reported by Chatterjee et al..$^{15}$ and Franciosa et al. ${ }^{16}$ In this study, treatment with hydralazine alone produced a small but significant reduction in arterial and pulmonary wedge pressure which differs from the results of Chatterjee et al..$^{15}$ and may be related to the larger dose of hydralazine used, to the different composition of two relatively small groups, and to the variation of metabolism of hydralazine in different patients. The blood levels of the active metabolites of hydralazine are dependent on the individual rate of hepatic acetylation when the drug is given orally; the blood level of hydralazine is approximately 50 per cent of the oral dose in slow acetylators but only 30 per cent in fast acetylators.

The reduction in left ventricular filling pressure after treatment with hydralazine is a probable consequence of more effective left ventricular emptying resulting from decreased impedance to ejection. This reduction in diastolic pressure and volume will result in an improved oxygen demand: supply ratio which will prevent or delay myocardial ischaemia during stress in patients with ischaemic cardiomyopathy and thus help to preserve myocardial function.

During peak exercise the magnitude of change in cardiac output after treatment with hydralazine is less obvious for the group overall than that observed under resting conditions. This is an expected finding, since it would be very unlikely, that under conditions of stress, impaired pump function would be able to improve as much as at rest however potent the stimulus. In addition, quite distinct variations between patients in the increment in cardiac output during exercise after hydralazine were observed and this probably related to the aetiology of the heart failure, its severity, and duration. Exercise tolerance in all patients, when assessed after the acute administration of hydralazine, was not improved even in those subjects where a considerable increase in cardiac output had been measured during maximal exertion. It is possible, therefore, that hydralazine results in an increase in cardiac output which is preferentially distributed to cutaneous, hepatic, splanchnic, and renal vascular compartments. ${ }^{11} 20$

In conclusion this study confirms the beneficial effect of hydralazine on resting cardiac function in patients with chronic heart failure. This improvement in cardiac function is sustained, though to a lesser extent, during upright exercise. Though these results provide further support for the use of vasodilators in the long-term management of patients with chronic heart failure, questions arise concerning the wide individual patient variation in response to treatment. Furthermore, though cardiac output is increased by hydralazine, more information about the regional vascular effects of such agents is required.

\section{References}

1 Franciosa JA, Guiha NH, Limas CJ, Rodriguera E, Cohn JN. Improved left ventricular function during nitroprusside infusion in acute myocardial infarction. Lancet 1972; i: 650-4. 
2 Chatterjee K, Parmley WW, Ganz W, et al. Hemodynamic and metabolic response to vasodilator therapy in acute myocardial infarction. Circulation 1973; 48: 1183-93.

3 Chatterjee K, Parmley WW, Swan HJC, Bierman G, Forrester J, Marcus HS. Beneficial effect of vasodilator agents in severe mitral regurgitation due to dysfunction of subvalvar apparatus. Circulation 1973; 48: 684-90.

4 Guiha MH, Cohn JM, Mikulic E, Franciosa JA, Limas JC. Treatment of refractory heart failure with infusion of nitroprusside. $N$ Engl f Med 1974; 291 : 587-92.

5 Miller RR, Vismara LA, Zelis R, Amsterdam EA, Mason DT. Clinical use of sodium nitroprusside in chronic ischemic heart disease. Circulation 1975; 51 : 328-36.

6 Bolen JL, Alderman EL. Hemodynamic consesequences of afterload reduction in patients with chronic aortic regurgitation. Circulation 1976; 53: 879-83.

7 Mason DT, Braunwald E. The effects of nitroglycerin and amyl nitrite on arteriolar and venous tone in the human forearm. Circulation 1965; 32: $755-66$.

8 Miller RR, Vismara LA, Williams DO, Amsterdam GA, Mason DT. Pharmacological mechanisms for left ventricular unloading in clinical congestive heart failure. Circ Res 1976; 39: 127-33.

9 Armstrong PW, Walker DC, Burton JR, Parker JO. Vasodilatory therapy in acute myocardial infarction. Circulation 1975; 52: 1118-22.

10 Williams DO, Amsterdam EA, Mason DT. Hemodynamic effects of nitroglycerine in acute myocardial infarction. Circulation 1975; 51: 421-7.

11 Freis ED, Rose JC, Higgins TF, Finnerty FA Jr, Kelley RT, Partenope EA. The hemodynamic effects of hypotensive drugs in man; $4: 1$-hydrazinophthalazine. Circulation 1933; 8: 199-204.
12 Stunkard A, Wertheimer L, Redisch W. Studies on hydralazine; evidence for a peripheral site of action. f Clin Invest 1954; 33: 1047-53.

13 Rowe GG, Huston JH, Maxwell GM, Crossley AP Jr, Crumpton CW. Hemodynamic effects of 1-hydrazinophthalazine in patients with arterial hypertension. f Clin Invest 1955; 34: 115-20.

14 Ablad B. A study of the mechanism of the hemodynamic effects of hydralazine in man. Acta Pharmacol Toxicol 1963; 20, suppl I: 53.

15 Chatterjee K, Parmley WW, Massie B, et al. Oral hydrallazine therapy for chronic refractory heart failure. Circulation 1976; 54: 879-83.

16 Franciosa JA, Pierpont G, Cohn JM. Hemodynamic improvement after oral hydrallazine in left heart failure. Ann Intern Med 1977; 86: 388-93.

17 Stead EA Jr. The role of the cardiac output in the mechanisms of congestive heart failure. Am $\mathcal{f} \mathrm{Med}$ 1949 ; 6 : 232-6.

18 Chidsey CA, Harrison DC, Braunwald E. Augmentation of the plasma nor-epinephrine response to exercise in patients with congestive heart failure. $N$ Engl f Med 1962; 267: 650-4.

19 Zelis R, Mason DT, Braunwald E. A comparison of the effects of vasodilator stimuli on peripheral resistance vessels in normal subjects and in patients with congestive heart failure. $\mathcal{F}$ Clin Invest 1968 ; 47: 960-70.

20 Johnston BM. The use of radioactive microspheres to compare the effects of hydralazine, guanethidine and SK and F 24260 on the redistribution of cardiac output in anaesthetized rabbits. $\mathrm{Br} \mathcal{F}$ Pharmacol 1975 ; 55 : 393-402.

Requests for reprints to Dr William $\mathbf{R}$ Ginks, Cardiac Department, St. George's Hospital, Blackshaw Road, London SW17. 